\title{
Coloniality-Decoloniality and Critical Global Citizenship: Identity, Belonging, and Education Abroad
}

\author{
Eric Hartman \\ Nora Pillard Reynolds \\ Haverford College
}

Caitlin Ferrarini

University of Massachusetts Boston

Niki Messmore

Indiana University

Sabea Evans

Lagim Tehi Tuma

\section{Bibi Al-Ebrahim \\ Amizade}

\section{John Matthias Brown}

Association of Clubs, Westmoreland, Jamaica

\begin{abstract}
:
This article draws on existing literature, a large, multi-institutional dataset, and several case studies to explore two empirical questions: Do students of color (SOC) differ from white students in statistically significant ways in respect to the global learning goal of cultural humility? And what interactive effects do students and faculty from diverse backgrounds, diversity and inclusion advocacy, and diverse community contexts have on one another? We draw on existing literature and quantitative data to demonstrate that SOC tend to bring strengths to global learning experiences. We share several case studies to demonstrate how those strengths may lead to specific alliances regarding justice work in host communities, complicating any conception of students as visitors unattached to local justice struggles. Throughout the article, we draw on current literature and practice to present several questions at the intersections of education abroad, diversity, equity, inclusion, community-based global learning, and critical global citizenship.
\end{abstract}

\section{Introduction}

In the article that follows, we upend and complicate numerous assumptions at the intersection of participant diversity, global learning goals, inclusivity and justice advocacy, and host communities. In particular we demonstrate that students of color (SOC) bring specific assets and cultural wealth to education abroad programming, and that individuals with marginalized identities frequently interact with host community justice networks in both exciting and profoundly complicated ways, 
presenting numerous new questions regarding appropriate preparation, mentorship, and even conceptions of right action in host communities.

We begin by drawing on existing literature on experiences of SOC abroad. While highlighting some of the tensions present in that literature, we integrate indigenous scholars' discussion of individuals' and institutions' simultaneous roles in coloniality and decoloniality. We consider how that discussion relates to the often-dichotomizing cultural reproduction in education abroad. Taking an asset-based approach to identity, we draw on cultural wealth to consider how historically marginalized students bring strengths to global learning.

We include lengthy student voice excerpts from other literature, as well as case studies and additional student quotes below, as part of our effort to ensure authentic voices of historically marginalized students and community members are present in an article that also aspires to leverage the power of multi-institutional cross-context data and understanding. Despite centuries of intellectual production imagining otherwise, personal knowledges and academic knowledges are interlocking (Russel y Rodríguez, 2007). The journal article format often incidentally reasserts a worldview that separates discipline, method, and context, reducing the complexity of lived social phenomena (Schram, 2012). It is our hope that aggressive co-authorship, mixed methods, direct quotation, and a fairly broad review of relevant literature will aid us in better presenting the interlocking complexity of the dynamics we aim to navigate.

Taken together, this review of existing literature situates our work and our identities (as students, staff, and faculty members) within institutions, communities, and cultures that are simultaneously complicit, critical, and aspirationally liberatory. Liberatory work seeks justice for one and all. Students and academic professionals often resist or wish to resist injustice across education abroad contexts, and the cultural wealth literature suggests historically marginalized students may bring specific related strengths. We find the conventional education abroad learning goal of intercultural competence insufficient for the intersections of identity, understanding, and resistance, and therefore draw on the literature to introduce cultural humility as a related but distinct global learning goal. We illustrate the relevance of cultural humility to education abroad practice through the first of three case studies.

With the relevance of cultural humility established in theory and in practice, we draw on a large data set to analyze one specific question: Do SOC self-identify cultural humility strengths in a manner that is statistically different from white students? As we establish a relationship between student identity and the presence of self-reported indicators of cultural humility, we continue to complicate the interactions between participant identity, local community context, and diversity and inclusion advocacy. Our final case studies examine varied diversity across community contexts, suggesting still more factors for consideration. We close with implications, including a call for robust engagement with critical global citizenship for individuals advancing inclusivity and equity across cultural contexts.

\section{Identities at Home and Abroad: "Students of Color" and "White" Students}

One of this study's authors, Messmore, was in a study abroad experience in the Republic of Trinidad and Tobago, a country with historical and contemporary relationships with the violence of colonialism, the genocide of indigenous peoples, the institution of African slavery, and the 
indentured servitude of Indians (individuals from the subcontinent of India). Prior to departure, one white male student was unwavering that he never saw race, just people. While not understanding it at the time, this student was engaging in "colorblindness," one of the central tenets of critical race theory (Delgado \& Jean Stefancic, 2017). Critical race theorists observe, "the notion of colorblindness fails to take into consideration the persistence and permanence of racism and the construction of people of color as Other" (DeCuir \& Dixson, 2004, p. 29). Yet in a country comprised of people of color, the white male student was overwhelmed by the new experience of being a racial minority. On the other end of the spectrum, the one Black $^{1}$ female student was incredulously happy because she had never been in a place where she was not the minority. Through reflection discussions, students representing white, Black, Asian, and Caribbean Latinx identities shared their perspectives and the white male student realized that he did recognize race now that he was a racial minority in Trinidad, and he learned from the labor of his peers who were students of color. Meanwhile, the study abroad experience was seen as especially affirming for the students who were Black and Caribbean.

Other scholars have documented complex relationships between education abroad participants' identities and their experiences, learning, and challenges in host communities. In a qualitative study of Black students participating in an Afrocentric education abroad experience in South Africa, Lee and Green (2016) documented students' deepened academic interests and long-term goals, stronger understanding of research, and better understanding of their own racial identities. One student reflected:

South Africa really helped me to come to terms with the complexities of identity . . . before I would identify as African over Black . . . this need to assert this identity over that identity and going back and forth between the two . . . but being there and seeing Black Americans interact with Black Africans and this cultural exchange . . this is your perception of us and this is our perception of you ... these are the common experiences that we have, helped me to come to terms with the fact that identities are complex and you don't have to find one space or one box to fit yourself in. (p. 70)

In a study examining first-generation Latinx students' experiences as part of an education abroad program in Costa Rica, Wick et al. (2019) also documented increasingly nuanced conceptions of identity:

I have always thought of myself as Mexican ... even though I have lived in Southern California practically all of my life. Nevertheless, as I reflected on my experience and the similarities/differences between my Mexican culture and that of the Costa Ricans, I have to acknowledge that my identity is also influenced by the American culture ... This was something that I don't think I had given much thought to in the past and which brought me a new perspective about myself when I reflected upon it. (p. 74)

The Wick et al. (2019), Lee and Green (2016), and Chang (2017, discussed below) studies all explore a gap in the education abroad literature (Contrearas, López-McGee, Wick, \& Willis, 2019) by detailing the experiences of minoritized students, and by doing so from an explicitly asset-based orientation. In each case and in others (Padrón, 2018; Sweeney, 2013), we see increasingly textured

\footnotetext{
${ }^{1}$ We capitalize Black when referring to people of the African Diaspora (Tharps, 2014).
} 
and rich self-understandings and narratives conveyed to the education abroad community. Yet these qualitative studies also reveal specific tensions that surface as students experience identities across contexts.

\section{Colonial Structures, Decolonizing Desires: Education Abroad Entanglements}

Numerous studies and initiatives aim to improve access to education abroad among students of all backgrounds (Hamir \& Gozik, 2018). Yet, "more work needs to include the systematic investigation of the differences in student experiences while abroad based on student identity" (Lopez-McGee, Comp, \& Contreras, 2018, p. 32). Chang (2017) wrote about Latinx students' experiences as part of a predominantly white study abroad group participating in a 4-week study abroad program in the Guatemalan highlands city of Cahikel in 2014. The students Chang interviewed struggled with ways in which their complex identities pulled them toward and pushed them away from Guatemalan peers and community members. One student reflected,

Despite myself, I found I was attracted to what I would call the tourists/western shops and stores ... like the touristy coffee shop some gathered in ... I feel as if I am walking a precipiceI am so worried about offending people and being the 'ugly American,' and maybe I am trying too hard. Even when buying and, thus, fail to bargain. But is my so-called progressive liberal attitude a 'do good' attitude that does more harm than good? Am I guilty of passing judgment on people based on what I think is in their best interest without taking into account their feelings? I want to give them what I think is fair . . . is this just 'still' a residual colonialist attitude? (pp. 15-16)

Wick et al. (2019) also documented tensions at the intersection of felt belonging or diasporic solidarity and economic inequity.

The thing that makes me feel guilty is that I almost feel spoiled. Even if I grew up with the family that had low income and we're probably looked down as the disenfranchised groups and the minority as a woman and a Mexican-American, but then I see these countries that they need so much and I'm kind of like, oh my gosh. Here I am thinking that I am low income, and I am, but I have a roof over my head and I have a bed and I have food, you know. (p. 75)

The student reflections shared here embody deep consideration of personal identity situated across multiple socio-economic contexts and local and global struggles for justice. Even to the point of considering how one shops or where one buys coffee, students are grappling with their identities as self-understandings that are situated in context and practice. In A Third University is Possible, decolonization scholar la paperson writes, "My position is impossible, a colonialist-by-product of empire, with decolonizing desires. I am, and maybe you are too, a produced colonialist" (2017, p. xxiii). We argue here that increasing attention to the strengths and nuances of underrepresented students' participation in education abroad highlights the ways in which the practices of education abroad continue to embody colonial tendencies (Zemach-Bersin, 2007, 2008), albeit, perhaps, within new, critically informed visions of co-creating "imaginary homelands" (Fiedler, 2007, p. 56, drawing on Rushdie) that provide space for our (re)negotiations of our postcolonial identities. Rather than attempt to avoid these tensions, we should walk toward them.

We are diversely-identifying and diversely-situated practitioner-researchers and civic actors, writing about underrepresented students (a population in which some but not all of us have recently 
been members) in the context of various local initiatives for equity and inclusion that we support; several of us write from higher education institutions. Our predicament within the education abroad and higher education sectors reminds us of Tuck's (2009) "argument for desire as an epistemological shift" (p. 419).

As a theoretical concept, desire interrupts the binary of reproduction versus resistance. In social science, it is often believed that people are bound to reproduce or replicate social inequity or, on the flip side, that they can resist unequal social conditions. Critics on both sides accuse the other of oversimplifying, or underestimating the immense and totalizing power of systematic oppression on the one hand and the radical power of the human spirit and human agency on the other. . . . Desire. . is neither/both/and reproduction and resistance. This is important because it more closely matches the experiences of people who, at different points in a single day, reproduce, resist, are complicit in, rage against, celebrate, throw up hands/fists/towels, and withdraw and participate in uneven social structures-that is, everybody. (pp. 419-420)

Tuck and paperson's incisive expressions of identity, desire, and coloniality/decoloniality provide helpful frameworks for considering the education abroad sector. Increasing diversity, equity, and inclusion is an effort to move toward greater justice. Yet it is possible that inclusion may only serve to visibly diversify colonial structures. That is not where the conversation or processes must end, however, as increasing diversity coupled with ongoing critique and consideration highlights the problematic nature of many of our sector's entrenched practices, calling us to consider new ways of thinking and operating that are ultimately even more inclusive through deep engagement with questions of equity. We offer cultural humility below as one example of a concept birthed through wrestling at the intersection of settled understandings like intercultural competence, coupled with deeper appreciation of historic and structural oppressions, inequities, and processes.

\section{Even as 'We' Diversify, We Often ReCertify Hegemonic, Dichotomizing} Narratives

At the turn of the last century, Landau \& Moore (2001) concisely expressed the conceptual cages that the field of education abroad needed to leave behind, namely assumptions imagining:

The greater antiquity and cultural prestige of the study destination; a general "racial" sameness between the (white) U.S. study abroad participants and their European hosts; a historical and cultural divide such that there was only rarely direct familial or affective connection between the student and the study destination; a relative homogeneity among the U.S. students; a roughly equal economic status of the sending and receiving nations; a destination culture historically not heavily affected by a wholly foreign U.S. culture; and finally a destination culture relatively unaffected by the American student presence. (p. 25)

Landau \& Moore's critique may be somewhat dated, as increasing numbers of SOC participate, and students are going to a greater diversity of receiving communities than ever before (Institute of International Education, 2019). But we must note that today's mid-career and senior professionals in the sector would have studied abroad during or before the era Laundau and Moore described. Further, many of the theoretical models at the intersection of student development and intercultural learning theory, still pre-eminent in the field, date from that era (e.g., Bennett, 1993; Deardorff, 2006; Evans, Forney, Guido, Patton, \& Renn, 2009). 
Through conceptual inheritance and professional conditioning, dichotomizing and simplifying patterns persist not only within the practices of education abroad offices, but also in the (re)production of the broader fields and cultural discourses in which education abroad is located. Caton and Almeida Santos (2009) employ discourse analysis to clarify the ways in which at least one major education abroad provider "continues to (re)produce hegemonic depictions of nonWesterners, asserting a Western superiority ideology by polarizing the West and the Rest into binaries of modern-traditional, technologically advanced-backward, and master-servant and decomplexifying the globalization process by presenting the non-West as exotic, culturally pristine, and filled with happy natives" (p. 191). These observations are not isolated (Brown, 2013; Gathogo \& Horton, 2018; Onyenekwu, Angeli, Pinto, \& Douglas, 2017).

Recent comprehensive reviews of multiple large institutions reveal ongoing biased cultural reproduction in the field of education abroad. Onyenekwu et al. (2017) conducted a systematic review of images utilized in marketing and communications at a major Midwest university. They found the images "consistent with previous studies that portray non-Western environments as culturally inferior, stagnated, and needing of intervention by the West" (p. 79). Onyenekwu et al. indicate that the images do nothing to complicate or challenge the ways in which "a 'White Savior' represents "unintentional, passive, 'colorblind' or dysconscious racism"” (Brown, 2013, p. 131), which impedes critical conversations about the global structures privileging and oppressing" (p. 71). Bishop conducted a review of the visual and verbal framing on the websites of the three US universities that sent the most students abroad during the 2009-10 academic year. Among other findings, she documented, "None of the photographs feature a student figure who has darker skin than the depicted members of the host culture. In almost every photograph, the students appear to be Caucasian" (2013, p. 403).

Not only do these approaches to advertising and promotion recertify damaging narratives and inaccurate histories, they also serve to perpetuate low enrollments in education abroad from SOC (Gathogo \& Horton, 2018). Gathogo and Horton note, "electronic SA [study abroad] ads position White students as the 'right people' to study abroad while everyone else, by implication, belongs to the 'wrong group.' By using images of and testimonials from White students almost exclusively, SA program providers risk sending the message that SA is a preserve of white students" (2018, p. 71).

Beyond education abroad, in the campus-community engagement literature, scholars remain concerned that programming "places the onus on communities to teach students about 'real world systemic inequality' through the lens of their experience” (Santiago-Ortiz, 2019, p. 45). And yet, growing understanding of the new majority student illuminates a much more diverse and complex campus than has ever existed before. We education abroad staff, faculty, and students are regularly reproducing and resisting dichotomizing and colonizing tendencies. Yet the contribution of cultural wealth discussed below reveals that some of us students, faculty, and staff may be especially wellprepared to recognize and resist systemic injustices.

Underrepresented Students' Strengths, Presence, and Community Cultural Wealth

Living in tension and contradiction is true not only among individuals, but also whole systems and social patterns. General racial sameness among U.S. education abroad students, for instance, is 
decreasingly true. The institutions and programs considered here are themselves diverse, including minority-serving institutions (MSIs), large public institutions, and liberal arts institutions - all of varying selectivity. The dataset discussed below is drawn from the Global Engagement Survey (GES). Demographic distribution from the GES is compared to demographic distribution in the United States, and within education abroad, as follows:

Table 1. Diversity within GES Data Set, United States, and Education Abroad

\begin{tabular}{|l|l|l|l|}
\hline & GES Data Set & U.S. Census & Education Abroad \\
\hline African American & $11.5 \%$ & $13.4 \%$ & $6.1 \%$ \\
\hline Asian or Pacific Islander & $13.3 \%$ & $6.1 \%$ & $8.2 \%$ \\
\hline Latino & $10 \%$ & $18.3 \%$ & $10.2 \%$ \\
\hline White & $53.6 \%$ & $60.4 \%$ & $70.8 \%$ \\
\hline Other / multiple & $11.3 \%$ & $2.7 \%$ & $4.3 \%$ \\
\hline Urban & $14.6 \%$ & $31 \%$ & Not available \\
\hline Suburban & $63.5 \%$ & $55 \%$ & Not available \\
\hline Rural & $22 \%$ & $14 \%$ & Not available \\
\hline
\end{tabular}

Sources: Global Engagement Survey, academic years 2014-15 through 2017-18; United States Census Bureau (2019); Parker, K., Menasce Horowitz, J., Brown, A., Fry, R., Cohn, D., \& Igielnik, R. (2018) (the two preceding sources draw on data that is older; sourced from the 2010 census); Institute of International Education (2018) (drawing on data from the 2016-17 academic year).

Reviewing data on study abroad participation suggests student participation increasingly mirrors population distribution in the United States. However, growing diversity does not inherently disrupt the many assumptions embedded within education abroad discourse and practice (Hartman, 2016, 2017; Landau \& Moore, 2001), education abroad marketing teams' reproduction of colonialist narratives (Caton \& Almeida Santos, 2009; Brown, 2013; Gathogo \& Horton, 2018; Onyenekwu et al., 2017), or the ways in which white students may quickly embrace stereotypes as tools of understanding and classifying in Global South communities (Chang, 2017). Diversity may increase even as inclusive excellence falters (Lopez-McGee, Comp, \& Contreras, 2018; Sweeney, 2013). As indicated above, our dataset provides an opportunity to examine strengths that historically underrepresented students may bring to global learning programs. First, we clarify our theoretical grounding through consideration of community cultural wealth.

\section{Community Cultural Wealth}

Community cultural wealth is a concept and practice within critical race theory (CRT) that aims to empower through valuing the strengths people of color (POC) have learned from their families and communities. Conceptualized by Tara J. Yosso, community cultural wealth is "an array of knowledge, skills, abilities and contacts possessed and utilized by Communities of Color to survive and resist macro and micro-forms of oppression" (Yosso, 2006, p. 77). Community cultural wealth challenges deficit theorizing, especially traditional Bourdieuean cultural capital theory, which posits 
that POC lack cultural capital as defined by white middle-class values (education, language, social networks, money, etc.) resulting in social and academic disadvantage (Bourdieu \& Passeron, 1977). As an asset-based theory, community cultural wealth instead values the knowledge, experiences, and skills that SOC acquire through navigating and resisting oppression.

Yosso applies community cultural wealth to SOC and education by identifying six forms of cultural capital: aspirational, navigational, social, linguistic, familial, and resistant. The community cultural wealth lens envisions culture broadly as shared behaviors and values that hold race and ethnicity as central elements, but culture also includes intersecting identities such as immigration status, gender, phenotype, sexuality, and region (Yosso, 2006, p. 76). The following is a very brief summary of the six forms of capital according to the conceptualization of community cultural wealth. The detailed description of the six forms of capital can be found in Yosso (2006). It is important to note that these are fluid forms of capital, which interact and build on one another, and are intended to apply to SOC. Aspirational capital is the learned sense of resilience, possibility, and hope for a better future that SOC possess despite real or perceived barriers. Linguistic capital refers to the valuable linguistic and cross-cultural communication skills that many SOC possess. This includes skills such as storytelling, memorization, and communication through art and music. Familial capital refers to a broad understanding of kinship and community well-being which prompts many SOC to value the resources that come from community connection. Social capital includes knowledge of how to utilize social networks to navigate institutions such as educational, legal, and health care systems. Navigational capital includes personal skills and coping mechanisms that allow SOC to move through institutions that ignore or are hostile to POC. Resistant capital refers to the "knowledge and skills fostered through oppositional behavior that challenges inequality" (Yosso, 2006, p. 80). SOC possess experiential knowledge of racism and inequality as well as practice in resisting, and perhaps even transforming, these oppressive systems. Knowingly or unconsciously, SOC bring these valuable forms of cultural wealth to the study abroad experience and the encounter with diverse cultures and people abroad.

From Self-Understanding and Effective Communicating to Co-Imagining and Rebuilding: Embracing Cultural Humility

Community cultural wealth helps illuminate the ways in which SOC have abundant resources that may serve SOC, communities abroad, and fellow participants in education abroad programs. But it is a concept that grew from Critical Race Theory (CRT) as situated in the specific histories of the United States. The field of education abroad has seen some applications of CRT (Chang, 2017; Wick et al., 2019), but in large part the field has situated itself within a discourse around intercultural competence that suggests it is "the ability to communicate effectively and appropriately in intercultural situations based on one's intercultural knowledge, skills, and attitudes" (Deardorff, 2006, p. 249). More recently, Bennett defined intercultural learning as "the acquisition of generalizable (transferrable) intercultural competence; that is, competence that can be applied to dealing with cross-cultural contact in general, not just skills useful for dealing with a particular other culture" (2012, p. 91). As implied above, the formative studies and research for these scholars took place during the era described by Landau \& Moore (2001). That does not suggest their research is wrong, but it does suggest that new complexities may be introduced with increasing diversity. 
One feature of existing research on underrepresented students in education abroad is that it often introduces concepts of diasporic identity or resistance to global forms of oppression.

Affirmed resistance and aspiration to inspire: As social work students, most participants in this study were likely aware of societal inequities and predisposed to notions of social justice in the United States. The opportunity to engage abroad, however, particularly in a country with lower economic indicators, appears to have underscored their commitment to social justice causes. (Wick et al., 2019, p. 77)

When done intentionally, study abroad trips are ideal spaces for these unique opportunities and can lead to liberating education for Blacks who have been historically mis-educated. (Lee \& Green, 2016, p. 73)

At times solidarity and social justice leads students past the conceptual construction of intercultural competence in its popular usage in education abroad, and toward taking particular stances regarding right and wrong action in both home and host country contexts.

All participants noted that the actual faculty members were overwhelmingly Ladino (rather than indigenous) and that the content of such lectures seemed to reflect a biased, often deprecating view of indigenous families, their educational aspirations and their traditional customs. Participants drew parallels to similar White supremacist orientations around U.S. schooling and neoliberal educational reforms in particular. (Chang, 2017, p. 17)

(Ladino refers to "a socio-ethnic category of Mestizo people in Central America especially in Guatemala” [p. 14]).

The case study we review here illustrates the simultaneous tensions students may find themselves in as they re-imagine and negotiate their own identities even as they resist global forms of oppression by allying with local collaborators. It also underscores the ways in which critical reflection and experiential learning may combine for "a learning process that recognizes and critiques ideology (political, economic, social, and cultural), uncovers hegemonic assumptions, and examines relations of power with the goal of becoming critically aware of how each distorts our worldview" (Hartman, Kiely, Friedrichs, \& Boettcher, 2018, p. 76). We turn now to the first of three case studies considered in this article.

\section{Case Study 1: Co-Creating the Black is Beautiful Project}

\section{By Sabea Evans}

In 2017, I spent the summer after my junior year at Haverford College as a Lagim Tehi Tuma fellow. Lagim Tehi Tuma (LTT), meaning “Thinking Together” in Dagbani, is an action research fellowship held in the northern region of Ghana that is offered in collaboration between Bryn Mawr and Haverford Colleges and the University for Development Studies-Tamale. Undergraduates from the three institutions participate in internships at community-led NGOs in Dalun, Dagbani language lessons, and local cultural art learning. The goal of the fellowship is "to study and explore questions of history, identity, and culture in the context of postcolonial power relationships" (Lesnick \& Bahn, 2018). The internships offered have recently expanded from placements at an early-childhood education center, a computer literacy center, and a community radio station to include planning "Black is Beautiful" workshops on skin bleaching. 
The Black is Beautiful Workshop internship grew out of a series of workshops informally planned by fellows and community members on the health hazards of skin-lightening products and ways to destabilize notions of colorism that informed their use. The conversations that led to the planning of the workshops began in 2014, after Black U.S. fellows noticed a combination of skin bleaching products being sold in town, and lighter-skinned fellows and community members drawing heightened attention (Lesnick, 2017). The fellows had identified an issue that had already been a clear concern of local community members in a way that tapped into their personal relationship to racism and colonialism and stepped into collaborative inquiry around the global nature of anti-blackness. The fellows used both their physical resources and their community cultural wealth as Black U.S. students to help facilitate a space for community conversation around the ways they could resist colorism and intervene in skin-bleaching. They also paved another path of motivation for other Black students to participate in LTT, engage with these close to home issues, and also hold a space for more intentional inquiry into ideas around "global" blackness. I participated in planning for the Black is Beautiful workshops both when I was a fellow in 2017 and when I returned to Dalun as a graduate coordinator for the most recent LTT cohort in 2019.

The question of who is identifiable as Black has precipitated ongoing conversation between Black U.S. fellows, Ghanaian fellows, and local community members. Not all fellows who are racialized (which often relates to their self-identification) as Black in the United States are considered by Ghanaian LTT interlocutors as able to identify as such within the Ghanaian context of blackness. The reasoning varies, e.g., skin color or national or tribal identity, and is largely tied to both conflicting narratives of the transatlantic slave trade and the historical presence of white-identified people in Ghana. In the 2017 cohort's workshop, U.S. fellows who identified as Black and white helped plan and facilitate the workshop. There was an assumption made that when a community member asked about what right the fellows held to speak about colorism and skin-bleaching, if the products and ideologies were brought by white people, the community member was directing the question to the white students. However, it was made clear later that community members conflate being light-skinned, being from the United States, and being white. Community members would gesture to Black fellows when referencing the skin color that people wanted to achieve by bleaching, referring to them as white while doing so. In hosting these workshops, ideologies that U.S. fellows, Ghanaian fellows, program mentors, and other community members had around race, identity, colonialism, and belonging were all exposed and put into conversation with one another for points of important learning for everyone involved.

The Black is Beautiful workshops required more structure, attention, and dedicated involvement in such important and complex ways that the project was made into an internship for the most recent cohort of LTT. In the most recent cohort of LTT, Ghanaian fellows and community members seem to have widened their perspective regarding which people from the United States are Black and have truly personal experience with issues around anti-blackness. Black U.S. fellows seem to also have been more prepared and resilient to differences in language and ideology around their identities as Black. However, the conversation that Black is Beautiful (and the general encounter that is LTT) prompts is still fluid and ongoing. In the most recent cohort of U.S. fellows, all students identified as Black but not all fellows identified as "Black American." Some fellows held strong ties to heritage from different African countries, made a distinction between "Black American" and "African American," and were vocal about their cultural heritage in a way that opened up even more 
complexity about who can lay claim to racialized experience and even who had rights to participate within Black identity.

In multiple discussions around colorism and colonialism, including those involved in the planning of Black is Beautiful workshops, the content was met with pushback from a Ghanaian fellow. The Ghanaian fellow believed that colonialism should invoke negligible regret, that colorism was self-inflicted, and that white people had done a favor to Ghana with the technologies that had been introduced via colonization. Many of the U.S. fellows had not been prepared for this disagreement because there had been an assumption that through sharing this Black identity, there would be shared ideologies and understandings of history that engaged Black people in a more sympathetic way. Due to this complex assumption, the conversation had space for respectful critiques that led to a shared understanding around the implications of colonization. At the same time, a conversation was strengthened around the nuances of identity, identity development around different racial ideologies and racializations, and global experiences.

\section{Clarifying and Measuring Cultural Humility: Identity and Patterned Differences}

We will continue to unpack the tensions in the case above, and other cases, while we also draw on data to determine if underrepresented students differ from other students' self-reported possession of cultural humility in statistically significant ways. In previous literature exploring the interaction of student identity and education abroad experiences, scholars have hypothesized that SOC may not be attracted to education abroad as an opportunity to improve intercultural communication skills, because they may already possess those skills (Salisbury et al., 2011; Sweeney, 2013). Yet scholars have not had the opportunity to examine these or similar possibilities through use of a large dataset.

Writing about needed research in respect to inclusion in education abroad, Lopez-McGee et al. (2018) assert, "there is a need for better and more robust institutional and national-level data" and "future scholarship should examine differences in learning outcomes based on student demographics, that is, whether students from certain demographic populations have different outcomes in intercultural competencies, language acquisition, and other competencies after going abroad" (p. 33). We now turn to an opportunity for understanding the strengths SOC bring in respect to those skills and learning goals.

\section{The Global Engagement Survey}

The Global Engagement Survey (GES) is a mixed-methods multi-institutional assessment of global learning outcomes, separated into the three categories of cultural humility, civic engagement, and critical reflection, drawing on the work of the Association of American Colleges and Universities (AAC\&U, 2014). The survey has been presented and is under review elsewhere, so the scale development and conceptualizations are not discussed here, though it is worth noting that the GES draws heavily on existing education abroad, global learning, and critical service-learning research, with particular attention to updating these ideas to include consideration of power and positionality, along with need for application (Bennett, 1993; Braskamp, Braskamp, \& Engberg, 2014; Green \& Johnson, 2014; Hartman \& Kiely, 2014; Mc'Tighe Musil, 2009; Morais \& Ogden, 2011; Porfilio \& Hickman, 2010). 
For the purposes of this article, we focus on one component of global learning: cultural humility, defined as:

A commitment to critical self-reflection and lifelong re-evaluation of assumptions, increasing one's capacities for appropriate behaviors and actions in varying cultural contexts. This capacity for appropriate, culturally relevant action is coupled with awareness of one's positionality within systems of power, and aligned in service of collaboratively re-considering and re-constructing assumptions and systems to enact a deeper and broader embrace of shared dignity, redressing historic inequities. (Hartman et al., 2018, p. 96)

Cultural humility was theorized through the applied fields of medicine and social work (Tervalon \& Murray-Garcia, 1998). It moves beyond intercultural competence's focus on appropriate action in other contexts (Bennett, 2012; Deardorff, 2006), acknowledging more explicitly that individuals frequently must-with some amount of simultaneity-negotiate new systems of meaning while resisting or responding to oppressive actions or systems. Within cultural humility as a conceptual construct, we focus here on a single subscale: Openness to Diversity (OD).

While the OD scale, which appears below in Table 3, was not specifically designed as a measure of community cultural wealth, it includes items that imply possession of linguistic, navigational, social, and resistant capital as described by Yosso (2006). A special feature of the GES is that openended, qualitative questions follow student responses to individual subscale items, depending on the student's response. These questions have been developed to provide opportunities for researchers to consider students' utterances as, depending on the question and response, evidence-based demonstration of learning (rather than self-report), confirmatory reflections, or reflections that negate self-report. We are including those qualitative questions in italics in Table 3.

Table 3: Openness to Diversity Subscale Items and Related OpenEnded Questions

- By interacting with people who are different from me, I have learned that I am flexible in my thinking and ideas.

- I am very comfortable talking about diversity with people of different cultures.

- If strongly agree (SA) or agree (A): Could you describe a point at which you get uncomfortable discussing diversity with people of different cultures?

- If strongly disagree (SD) or disagree (D): Can you indicate why you are uncomfortable discussing diversity with people of different cultures?

- I have a very strong appreciation of other nations, cultures, and customs.

- I am able to communicate in different ways with people from different cultures.

- When I am in a cultural space that is different from my home culture, I make efforts to adapt my language to include local language, sayings, or speech patterns.

- If SA or A: What is an example of a time you have adapted your language or speech patterns to improve your culturally appropriate communication? 
- When I am in a cultural space that is different from my home culture, I adjust my expectations and defense of personal space.

- I enjoy when my friends from other cultures teach me about our cultural differences.

- I am open to people who strive to live lives very different from my own lifestyle.

More information on this scale is available online (Campus Compact, 2019), and in other articles and chapters (Hartman, Lough, Toms, \& Reynolds, 2015; Lough, Reynolds, Hartman, \& Toms, under review), but we report some basic statistical validity confirmation here.

IRB approval was obtained through the appropriate institutional review boards at Westmont College and Haverford College during the course of the study. Reliability analysis of this scale indicates it has a Cronbach's Alpha of .78, suggesting it is a reliable scale. Over the course of three years, the survey has been administered to students from 30 participating institutions of higher education that operate 276 global learning programs. Aggregating respondents who took the survey from 2015 to 2017, 1,973 total students completed the pre-survey, and 1,089 total students completed the post-survey, with 673 students completing both pre- and post-tests, resulting in a total of 2,396 unique or independent cases. Most programs examined across the participating institutions could be described as: four weeks or less in duration, primarily with service-learning immersion experiences, completed outside of the United States. Roughly 15\% of participants did not have a service-learning component.

Six separate two-way repeated measure ANOVA tests were run to compare mean differences in students' scores on the "openness to diversity scale" split by two within-subjects factors including (1) time (pre-test to post-test) and (2) a demographic variable associated with cultural wealth [i.e., race $(1=$ White, $0=$ Non-white), ethnicity (1=Hispanic/Latino, $0=$ Non-Hispanic/Latino), selfidentified sex ( $1=$ female, $0=$ male), geographic upbringing $(1=$ student grew up in a suburban or rural setting, $0=$ student grew up in an urban setting), and country of birth ( $1=$ U.S., $0=$ non-U.S.)]. The dataset does not yet include a sufficient number of students who identify as transgender for a statistically robust analysis of the relationship between that identity and desired global learning outcomes, though the number continues to grow and that analysis may be possible in the future. All independent variables were recoded into binary categorical variables for the sake of exploratory analysis. Because all independents were bivariate, no post hoc tests were used in this analysis to determine differences between statistically significant interactions. The confidence interval for statistical significance was set at $95 \%$ or $a<0.05$.

Findings reported in Table 2 reflect interaction effect between time (baseline and post-program) and the five demographic variables. Scores have been reverse-coded so that a five score would reflect the scale's maximum possible openness to diversity, while a one would reflect the least possible openness on the scale. Two of the variables examined were statistically significant at the .05 level, and four of the five variables followed the expected pattern. The exception to the pattern was exhibited by students who self-identified as Latinx. As a cohort, their professed openness to diversity as a baseline measure indicated greater openness than was the case for any other group either before or after global learning programming. They were not, therefore, in a position in which 
they could have clearly increased their openness in terms of recognition on the scale. Post-program, they continued to indicate greater openness than any other group examined here.

Table 2. Openness to Diversity Baseline and Post-Program by Student Demographics

\begin{tabular}{|c|c|c|c|c|c|c|c|c|c|c|}
\hline \multirow[b]{2}{*}{ Time } & \multicolumn{2}{|c|}{ White/ SOC* } & \multicolumn{2}{|c|}{ Latinx/ Non-Latinx* } & \multicolumn{2}{|c|}{ Gender Identity } & \multicolumn{2}{|c|}{$\begin{array}{l}\text { Home: Urban or } \\
\text { Suburban/Rural }\end{array}$} & \multicolumn{2}{|c|}{ Birthplace: U.S. or Not } \\
\hline & W & $\mathrm{N}-\mathrm{W}$ & $\mathrm{L}$ & N-L & $\mathrm{M}$ & $\mathrm{F}$ & $\mathrm{U}$ & $\mathrm{S} / \mathrm{R}$ & U.S. & N-U.S. \\
\hline Baseline & 3.17 & 3.33 & 3.43 & 3.23 & 3.26 & 3.24 & 3.23 & 3.28 & 3.22 & 3.39 \\
\hline Post-test & 3.31 & 3.37 & 3.41 & 3.33 & 3.36 & 3.33 & 3.3 & 3.38 & 3.32 & 3.4 \\
\hline Sig. & 0.002 & & 0.026 & & 0.927 & & 0.49 & & 0.067 & \\
\hline
\end{tabular}

Table 3: Openness to Diversity

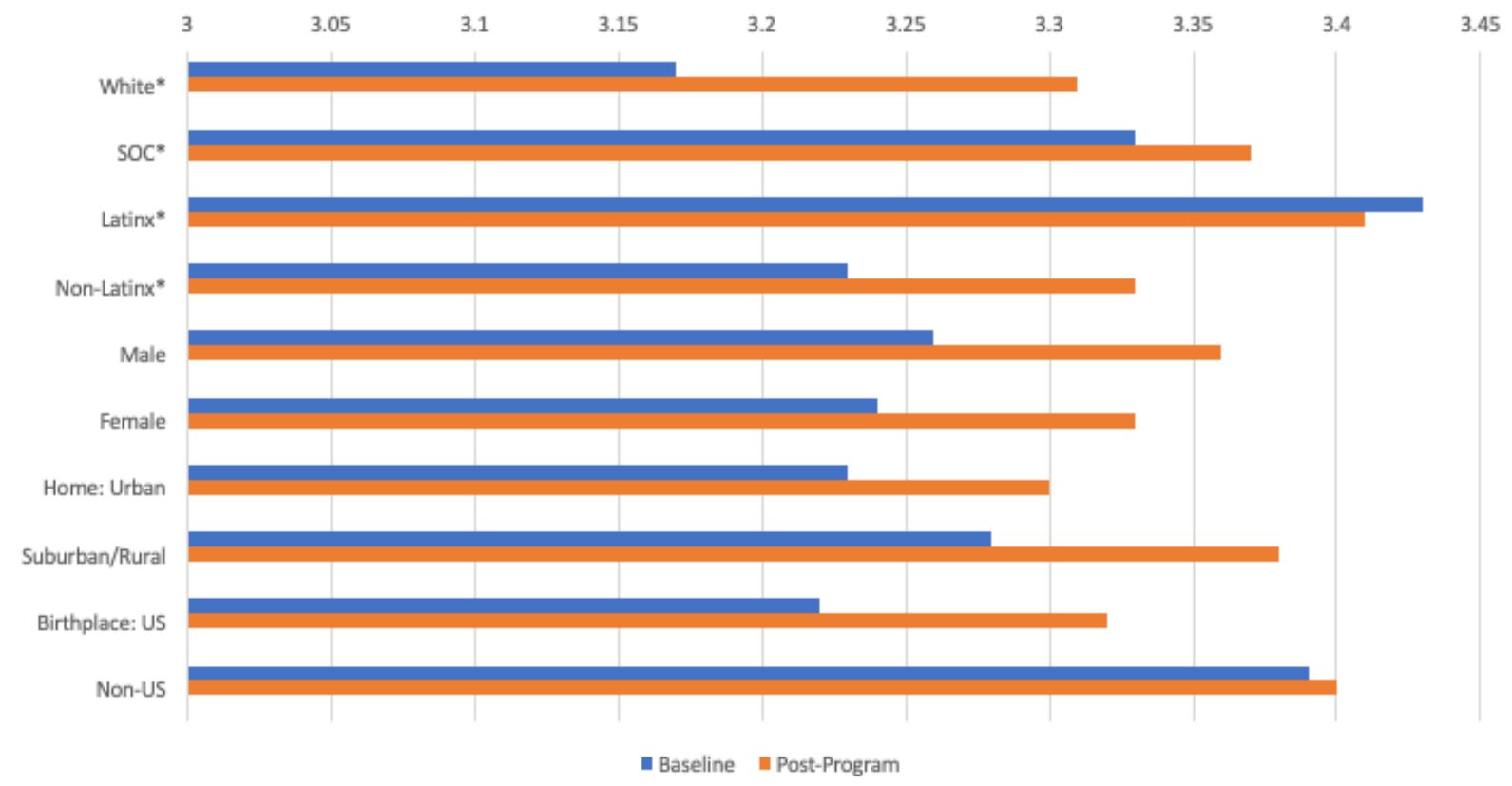

Statistically significant findings indicate that among students within this dataset, white and nonwhite, as well as Latinx and Non-Latinx students, exhibit statistically different self-reported openness to diversity. We also note that differences on the OD scale between students born outside the United States and in the United States neared statistical significance. SOC begin and complete global learning programs with greater self-reported openness to diversity than white students report possessing even at the completion of global learning programs. This finding confirms the implication of the community cultural wealth literature considered above: that SOC bring social and navigational resources to global learning experiences before they even begin to experience any programming. This finding is not surprising, and in qualitative comments SOC often shared how their identities required them to develop both navigational capital and intercultural skills in order to move through the university system, which is often hostile towards POC. A few striking examples: 
I'm a low-income woman of color studying at a PWI [primarily white institution]. I code-switch all the time.

I never shy away from topics of diversity because as a black person who is an African, I am a minority on campus and I believe that discussions on diversity are critical if we are to all gain an understanding of each other.

Because I am of a different socioeconomic and cultural background from most people on campus, I have been able to see how people think about certain social issues in different ways than I do, especially in the classroom.

In the conclusion we discuss implications of these findings for higher education professionals and researchers, both for practice and for further research. First, however, we observe that student qualitative comments from other open-ended questions in the GES reveal their awareness of the ways in which their identities may support efforts to connect with inclusion and justice advocates both locally and elsewhere around the world. We share several of those comments here, before considering two case studies that further illuminate and complicate host community justice work, diversity, and education abroad.

\section{Community Cultural Wealth and Resistant Capital}

The comments below are in response to this open-ended question in the critical reflection scale portion of the GES: Can you provide an example of how your education or applied experiences have helped you see communities that might otherwise remain unseen?

As a minority student at a predominantly white institution, I am aware of what it means to be invisible. More importantly, I work at the [Community Learning Center] where there are minority students who would otherwise be invisible that I choose to tutor.

I see communities that might otherwise remain unseen because I came from a community that was unseen. I grew up in poverty sleeping in the same room with my brother and sister, taken care of by a single mom who worked her ass off to ensure her children succeeded. I also grew up white in a white, upper middle class neighborhood. It was only in college that I realized the struggles I faced as compared to the struggles of my peers. Since embracing that identity I have been interested in exploring those unseen communities that exist all around.

I come from an immigrant family and have felt as though at times I was "unseen" so I tend to look for others in that same position.

As a person that identifies with marginalized identities, I tend to empathize with people who are also members of unseen communities. Through my education both formal and informal, I have been able to learn more about unseen communities and identities.

As illustrated through these reflections, students bring different forms of community cultural wealth to their university experience. Especially pertinent in these examples are the knowledge and skills of Yosso's resistant capital, which SOC often gain through the experience of resisting racism and inequality throughout their lives. However, as we will see in the case study below, inclusion expectations grounded in U.S. identities and assumptions sometimes meet resistance upon export.

Case Study 2: Disruption, Disconnection, and Solidarity: LGBTQ Rights in Jamaica 


\section{By Eric Hartman, Bibi Al-Ibrahim, and John Matthias Brown}

When I (Hartman) was first a staff member at Amizade, based in Pittsburgh, PA, in the United States, we began cooperating with the Association of Clubs (AOC), a community development and social solidarity network based in rural Jamaica. Our collaboration centered on a series of servicelearning and volunteering programs that would ultimately lead to the development of Fair Trade Learning (Hartman, 2015). Somewhat early in the relationship we had a question from one of the U.S. colleges we were working with: Would it be OK for a lesbian couple to take part in a program together? The answer was no.

In 2006, Time Magazine called Jamaica, "the most homophobic place on earth" (Padgett, 2006). As a direct implication, in our office in Pittsburgh, we often found ourselves advising LGBTQ+ folks away from Jamaica, or being clear with them about the limitations they might consider placing on their own self-expressions of identity if they chose to visit the AOC's home community of Petersfield. But of course, all the while, our Jamaican collaborators were gazing back at us (Prins \& Webster, 2010), and change processes were underway in Jamaica; activists were at work on the island. There and elsewhere, locally-rooted activists work for inclusivity and expose the colonial roots of the criminalization of homosexuality (Han \& O'Mahoney, 2018). Separately, the AOC meets weekly to discuss matters of importance to their network. Because they are involved in international partnerships, that discussion often turns to those collaborations.

As the AOC describes it, there have been a few specific instances that mark their shift toward LGBTQ+ inclusion, and are worth highlighting here. They are recounted as remembered by Petersfield Site Director, Mr. Matthias Brown.

In one situation, a university group with two trans students was visiting and attended a church service. As Christianity and involvement in a church community are culturally very important in Jamaica, as well as for many of the host families who are members of the AOC, visitors are often offered the option of attending a church service. During the church service, the preacher looked directly at the trans students, and began to preach about God's creation of "man and woman, Adam and Eve, not Adam and Steve." Mr. Brown at this point, very upset with the preacher, began to motion with his hands for him to stop. One of the trans students sitting close to Mr. Brown saw how visibly upset he was becoming, and whispered to him that it was okay, and that he shouldn't make a fuss. What Mr. Brown and others found to be so impressive about the situation was that at the end of the service, the trans student who told Mr. Brown not to worry approached the pastor to shake his hand with absolutely no anger. Despite the discriminatory language the preacher had so clearly directed towards the trans students, the student was still capable of approaching him with great respect. In addition to this, Mr. Brown remembers just how hard-working and loving the trans student was throughout the week of the program. The humanity that he and other AOC members saw in the trans students is what helped solidify their idea that assessing someone's character has nothing to do with sexual orientation or sexuality. ${ }^{2}$

\footnotetext{
2 The memory of this event led to significant discussion among co-authors. There is concern that this narrative suggests trans-identifying students must engage in emotional labor to educate host communities in such instances, and that education abroad professionals should ensure that is not the case. There is also a sentiment that the organizations involved were transparent about the context with LGBTQ+ students, and that students made their own
} 
Another moment in the AOC's history that highlights an internal shift in how the AOC functions concerns a host family that refused to accept an LGBTQ+ identifying student. Mr. Brown was of the opinion that the family should not discriminate in this way, and he took his concerns to be discussed with the other members of the host family committee. After discussion, the host family committee decided that host families should be welcoming of all visitors regardless of sexual orientation, or receive none. Since that moment, the host family in question is no longer a member of the committee.

In the course of several years and hundreds of guests, the community of Petersfield, and the AOC in particular, moved from resisting visits from out LGBTQ+ individuals to standing up as one of the first rural communities in Jamaica to publicly state that it would proudly host LGBTQ+ individuals in their community. Yet not one single program, policy, or agreement imagined that outcome. Rather, our colleagues in Jamaica heard repeatedly about gay and lesbian individuals interested in visiting their community. Some LGBTQ+ individuals visited as part of groups without being clearly "out." Our colleagues knew they were there but didn't know who they were. Then there were a couple of critical incidents, recounted above, that took place in the context of ongoing relationships, collaboration, exchange, and shared values of social solidarity.

\section{Making our Assumptions Visible: Culturally Contingent Rights, Diversity, Equity, Inclusion}

Without a doubt, on most U.S. college campuses and perhaps within most U.S. education abroad offices, advocating to stop colorism or to ensure LGBTQ+ inclusion are popular positions. Yet they are positions. They imply particular values.

Consistent with critiques of education abroad (Zemach-Bersin, 2007, 2008) and its discursive practices reviewed above (Bishop, 2013; Caton \& Almeida Santos, 2009; Onyenekwu et al., 2017) there are numerous forms of "soft" (Andreotti, 2006) or "thin" (Cameron, 2014) global citizenship. But critical global citizenship (Andreotti, 2006; Hartman et al., 2018) is "about conceptualising (and acting upon) injustice and inequality both locally and globally, and it intrinsically values concepts like alterity, difference and diversity" (Fiedler, 2007, p. 53). Attentiveness to localized justice struggles heightens our awareness of the culturally contingent nature of identity and values constructing notions of respect, rights, equity, and inclusion. Thinking seriously about social justice and culturally contextualized conceptions of truth requires the education abroad sector to turn with heightened seriousness to discussions of applied, robust global citizenship. We suggest:

Global citizenship is a commitment to fundamental human dignity, couched in a critically reflective understanding of historic and contemporary systems of oppression, along with acknowledgment of positionality within those systems; it connects with values, reflection, and

decisions regarding participation. In such a context, while this is not true all the time and under all circumstances (and should not be EXPECTED by students who identify as marginalized), an international education experience can lead to a student's genuine desire to share their identity for the purpose of educating others. This is not necessarily done out of obligation, but as a sincere gesture of engaging in the world towards change. We see no immediate resolution to the tension held between what higher education institutions can control, on the one hand, and local and global change processes on the other hand. The narrative here is co-created by host community members, organizational representatives, and other co-authors, who are positioned across Black, white, POC, U.S., Jamaican, cisgender, and LGBTQ+ identities. 
action. A critical global citizenship calls us all to humble, careful, and continuous effort to build a world that better acknowledges every individual's basic human dignity. (Hartman et al., 2018, p. 27)

We recognize the simultaneously colonial and decolonial aspirations baked into any conception of global citizenship - aspiring to leave states behind, but holding still to the language of identity and belonging born of statist imaginings: citizenship. We encourage colleagues to follow paperson's (2018) suggestion to disrupt higher education systems (inherently colonial themselves) toward decolonial or, at least, anti-oppressive ends. Our final case study highlights the extent to which mainstream cultural assumptions in the United States may be at odds with current host community traditions, creating spaces through which local activists may leverage visitors' presence toward more inclusive ends.

\section{Case Study 3: Community Activists Leverage Diversity for Gender Equity}

By Nora Pillard Reynolds

In 2002, I traveled to rural Nicaragua with a group of ten friends and ended up starting an organization, Water for Waslala (WfW), that has now raised over $\$ 600,000$ and built 18 community water systems serving over 5,000 people. In 2015, WfW was acquired by WaterAid and El Porvenir to form the Program Alliance Agua Para Waslala, which continues the work to ensure that all community members have access to clean drinking water. Since 2005, WfW and Villanova University's College of Engineering ( $\mathrm{CoE}$ ) have worked together to create international service experiences for engineering students. In the past 12 years, Villanova University's Engineering Service Learning program has sent over 250 engineering students and faculty on trips to Waslala to work on projects related to water distribution, mobile healthcare, and microhydro electrification (Reynolds \& Ermilio, 2015). Student participation ranges from one-week immersion trips to senior capstones to graduate field placements lasting six or more months. The partnership includes several different departments in the CoE, local community organizations in Waslala, and types of projects.

When faced with the daunting question of a dissertation topic, I ultimately decided to embrace my complicated positionality as practitioner-scholar in the partnership and explore community perspectives about this multi-year global service-learning partnership. In particular, I focused on Waslalan community members' perspectives about outcomes of this long-term (12+ years) partnership. The community participants described outcomes much more broadly than the university participants. In addition to tangible project outcomes such as improved access to health care, water, and electricity, the community participants also described confianza (trust), a sense of community pride, and consciencia (awareness) as positive community outcomes (Reynolds, 2016). Community participant perspectives drew attention to participation and interaction as equals as an important characteristic of this partnership.

Even having spent over 16 years working in this partnership, including scores of extended stays in Waslala, I was surprised by the following example of unintended outcomes as described by a woman in the community. In this case, the community narrator even emphasized how the presence of white men (the engineering program has been demographically similar to many engineering programs in the United States, with a preponderance of white men) who have been socialized in the United States provided her with opportunities to reinforce her work focused on women's rights. Her 
comments illuminated ways in which the presence of the university participants provided alternate examples of gender roles that supported education efforts carried out by the community organizations. Describing how the university trip participants each served their own food and washed their own plates during village visits, she stated:

It helps me a lot related to gender and how here the attitude of the Nicaraguan [men] is that they never serve their own food. They think they aren't able to serve themselves and they don't want to do it, or at least they are accustomed to the mamas always serving the food. So, it is important because it helps us to teach the farmers that they can serve their own food and then it is not such a large job for the mothers of the house. . They even mentioned it themselves. Dona X said to me, "how beautiful to see them serving their own food and washing their own plates."

\section{Findings}

We believe the combination of quantitative analysis and case study consideration provided here, in the context of the broader literature, confirms that historically underrepresented students tend to bring cultural wealth to global learning programs. This cultural wealth manifests in two ways that we were able to document here. The first is through the presence of navigational capacities that allow them to operate in and through diverse systems, cultures, and contexts. This idea is posited in cultural wealth theorizing, and confirmed here quantitatively through students' sense of their own openness to diversity, their self-reporting regarding navigating systems including their home campuses, and the facility (documented in the case studies in Ghana and Jamaica) with which they navigate complicated cross-cultural and justice challenges. The second form of cultural wealth documented here is related but distinct: resistant capital. Again in both Ghana and Jamaica, as well as in other cases documented in the literature (Chang, 2017; Lee \& Green, 2016), students bring experiences that lead them to see oppressive structures with a particular clarity, and we see instances of them allying with local justice advocates to resist those oppressive structures. In the Nicaraguan case study, we see a community member deploying both navigational and resistant capital to leverage the presence of education abroad students and faculty toward gender justice.

\section{Recommendations}

Theorists such as Homi Bhabha have pointed out, "in colonial discourse the space of the other is always occupied by an idée fixe [. . .]" (1994, p. 110). In other words, colonial discourse is primarily structured by a lack of recognition (Fiedler, 2007, p. 54).

We hope in our writing we have achieved at least two goals: first, presenting both "underrepresented students" and "host communities" in ways that represent a small portion of their/our great diversity, nuance, complexity, internal tensions, and agency; and second, by refusing to settle on a single methodology and immersing our analysis in education abroad in conversation with other literatures, bringing a portion of the real complexity of inherently interdependent, lived experiences to this writing. Embracing this complexity along with the need for program management and planning, we make several recommendations.

Recommendation 1: Deeper Engagement with Robust and Critical Global Citizenship 
As illustrated in our case studies, education abroad operates across multiple discourses of right action. At its best, as education abroad programming occurs, it simultaneously encourages all involved toward reflective consideration of the kinds of communities and worlds we wish to build together. In all of the cases we considered, visitors are aligned with locally-rooted networks to (ultimately) advance equity and inclusion. Yet visitors' advocacy is potentially problematic.

Several decades of education abroad assumptions suggest a primary goal of education abroad should be developing students' capacities to act effectively in local contexts, frequently involving respecting local cultural assumptions and ways of being (Vande Berg, Paige, \& Hemming Lou, 2014). Global development, global citizenship, and human rights history also make clear that outsiders entering with ideals to be implemented among local populations frequently encounter resistance, rejected ideals, and failed projects (Appiah, 2006; Hartman et al., 2018). Appiah writes, "Another aspect of cosmopolitanism is what philosophers call fallibilism-the sense that our knowledge is imperfect, provisional, subject to revision in the face of new evidence" (2006).

Recognizing that our students and institutions transcend campus-based, U.S.-national, international, and host community understandings of diversity, equity, and inclusion every time we engage education abroad programming, we suggest that the field must move to deeper engagement with learning goal constructs that hold the tension of cross-cultural respect and right action. We have presented cultural humility and critical global citizenship as constructs that simultaneously engage respect, listening, discernment, and judgment. While these are capacious concepts filled with internal tensions, we see several related, tangible steps forward.

\section{Recommendation 2: Reject any Conception of a "Typical Student"}

Most fundamentally for education abroad practitioners, program design must never be developed by imagining a "typical student." Further, given the historic inequities upon which education abroad rests, we respectfully and lovingly offer the suggestion that "the student" imagined by most individuals who have spent more than a decade being conditioned by the education abroad discourse may be a damaging archetype to allow to enter one's mind. Research and practice in education abroad should apply assets-based approaches, such as community cultural wealth, to working with SOC and other marginalized groups. For example, students with disabilities and LGBTQ+ students have also acquired valuable knowledge, experiences, and skills through navigating and resisting systems of oppression.

That said, GES openness to diversity data indicates that white students report being especially needy in the same desirable global learning skill sets and dispositions where SOC recognize themselves as especially strong. We understand this is merely social scientific data, so we see patterns that do not represent the complexities of any single individual, community, or context. But on average, if we are aiming to build inclusive campuses, communities, and beyond, white students continue to need systematic challenge and support to advance the development of their cultural humility and openness to diversity, even as programming must shift to meet SOC where they are and recognize their strengths.

It is worth noting that these findings relate to students who are likely to be opting-in to programs. An analysis of program administrators' characterization of the programs in the dataset indicates that most programs were either completely elective $(57 \%)$ or better described as "several 
students are here for requirements, but at least half are not" (30\%)." While the full socioeconomic diversity that exists within the U.S. white population complicates this to an extent, it seems reasonable to posit that most of the white students in this dataset are more likely to be disposed toward openness to diversity than white students who do not find opportunities to study abroad. (Alternatively, many of the white students in the dataset may simply be more likely to have comparatively large amounts of disposable income.)

\section{Recommendation 3: Integrate Education Abroad with On-Campus Inclusion and Diversity Efforts}

Taken together and considered in relation to broader national conversations on campus diversity, these data points help illuminate the structure of a specific tension experienced by many campuses and present in our qualitative data. SOC have stronger skills, assets, and dispositions in respect to OD. White students already disposed to engaging in cross-cultural and global learning programming have comparably fewer resources to draw upon. Many SOC and their allies are reasonably and defensibly frustrated by experiences of being repeatedly called upon to educate white students about race and diversity issues. White students disposed toward international and crosscultural programming are increasingly aware of this. We observe that these phenomena, taken together, may contribute to a freezing effect born of good intentions, in respect to on-campus diversity dialogues. Questions emerge regarding how and whether SOC might be called upon to contribute to campus community learning and if there is a way for such programming, recognizing SOC strengths and assets, to be appropriate and non-tokenizing. These findings and reflections reaffirm the vital need for campus-wide commitment to holistic, multi-year, institutional attention to diversity, equity, and inclusion (Milem, Chang, \& Antonio, 2005; Sweeney, 2013) that involves staff, faculty, and administrators in difficult and challenging dialogues regarding how campuses create inclusive and educative environments for all students throughout undergraduate experiences.

Recommendation 4: Professional Development and Programmatic Changes for Critical Understandings of Diversity, Equity, Inclusion, and Representation

In the education abroad sector, we suggest that all affiliated staff and professionals should familiarize themselves with critical discussions of race, systemic injustice, and cultural wealth in order to review existing or build new education abroad experiences, create meaningful pre-trip educational materials, and design opportunities for discussion and reflection within education abroad programs. This recommendation is rooted in our observations regarding the ways in which the sector's assumptions have arguably been formed by and are rooted in a different era, along with our documentation of several studies that clarify the ways in which dominant education abroad materials, promotions, and communications reproduce and reify stereotypes and dichotomization.

Several campuses provide examples of the ways in which faculty and staff can build challenging and supportive communities to discuss these topics as part of co-learning toward personal and institutional change. For example, Indiana University-Purdue University Indianapolis (IUPUI) started a "White Racial Literacy Project" to engage white faculty, staff, and students in education and reflection on whiteness (Denney, 2018). Additionally, utilizing the Institutional Excellence Scorecard developed by Sweeney (2013) can help professionals assess areas of current success and improvement for recruiting, supporting, and centering SOC in study abroad. Further, institutions that are serious about facilitating an inclusive educational experience for all students should dedicate 
resources to help their education abroad professionals participate in the kinds of personal and professional educational experiences that engage with race and systemic racism.

While recognizing this kind of work as vital, we also suggest that engaging these dialogues will be difficult, protracted, and necessarily experimental. As one effort-in-process that continues to meet with both positive results and adaptive challenges, the Haverford College Center for Peace and Global Citizenship (CPGC) attempted to directly address the challenges of cultural reproduction in the sector by flipping the typical photo contest toward an assignment built around ethical representation and awareness of co-advocacy efforts in cooperation with community organizations. The CPGC asked students to share photos on the themes of peace, social justice, and global citizenship. They shared several ethical photography frameworks with students, assigning them to be sure that they:

- Represent people truthfully and show dignity, support, and integrity.

- Ensure those being represented in the images maintain the right to share their story in their own way.

- Do not stereotype, sensationalize, or discriminate against people, situations, or places.

- Use images, messages, and case studies with the full understanding, participation, and permission of the subjects (or subjects' parent/guardian). (Haverford College, 2017)

Though the contest has generated a collection of images that do not fall to the same critiques mentioned above, strong students, employing critical lenses, have critiqued the contest as an institutional effort of self-promotion and marketing. Co-authors involved in the effort prefer to see it as an effort to responsibly leverage our tools toward improved ends, but recognize the legitimacy of the concerns raised by students, and find this instance to be another embodiment of the colonialdecolonial spaces in which critical global citizens and programs find ourselves.

\section{Recommendation 5: Systematically Approach Additional Research on Student Identity and Global Learning}

Beyond programmatic shifts, there are also several research questions related to student identity and global learning that emerge through this analysis, that could be answered through more sustained analysis of this or other datasets. In particular, we wonder about interactive and multivariate effects in respect to race, gender identity, and socioeconomic diversity among students who have been born and primarily live in the United States. Beyond the U.S. cohort, nearly statistically significant findings with respect to students who were born outside of the United States but attend U.S. institutions also presents additional focused research opportunities.

The GlobalSL Network has been engaged in this data collection effort as part of working with member campuses on their individual institutional assessments. The network is not staffed for ongoing research with this dataset, but is eager to work with faculty and graduate students who would like to draw upon the dataset to continue to build data-driven understanding in the fields of education abroad, civic engagement, and critical global learning.

Recommendation 6: Deepen Attention to and Understanding of Education Abroad Intersections with Host Community Justice and Human Rights Work 
Beyond students' personal development, identity interfaces with community members' experiences and inclusion activists' efforts in important ways. The case studies presented here demonstrate mechanisms by which student and faculty participant identities as women, LGBTQ+, African Americans, and/or SOC (and even cisgender white men) create unique opportunities for connecting to host community human rights and justice networks. We humbly posit that much of the education abroad, on-campus diversity, and civic engagement sectors have not grappled sufficiently with the complicated intersections of fallibilism, cosmopolitanism, colonial histories, ethical community engagement, global human rights activism, and student and faculty preparation and support. As student diversity increases on U.S. campuses and among education abroad programs emanating from the United States, host community conversations on equity and inclusion will increasingly connect with formal and informal education abroad programing. Education abroad professionals should engage with the literature on ethical community-campus collaboration to anticipate and appropriately prepare for related challenges and common pressure points (Collins, 2019; Hartman et al., 2018). More research on campus-community partnerships is needed as well (Larsen, 2015; Mogford \& Lyons, 2019), particularly at this intersection of growing student diversity, campus-community engagement programming, and their interface with community inclusion and equity efforts around the world.

Full engagement with equity and inclusion work that crosses cultural and national borders requires robust understanding of human rights as historically and culturally contingent expressions of values. We will improve our capacities to support our students where they are, and improve our capacities to collaborate with community partners appropriately, the more we recognize that this is essential shared work across the traditional mission of higher education to create critically-reflective, publically-serving graduates. It is part of the civic engagement movement, intersecting with the conventional mission of international education to slowly nurture peace by pieces, reducing barriers and stoking understanding of a global community of shared possibility and connection (Hartman et al., 2018).

\section{Acknowledgment:}

Eric Hartman would like to thank Rebecca Tiessen, University of Ottawa School of International Development and Global Studies, for a brief visiting professorship that provided the time and space that led to the first draft of this article.

\section{References}

American Association of Colleges and Universities (AAC\&U). (2014). VALUE: Valid assessment of learning in undergraduate education. Washington, DC: American Association of Colleges and Universities.

Andreotti, V. (2006). Soft vs critical global citizenship education. Policy and Practice. A Development Education Review. 3, 40-51.

Appiah, K. A. (2006, January 1). The case for contamination. The New York Times Magazine, pp. 30-37.

Bennett, M. (1993). Towards ethnorelativism: A developmental model of intercultural sensitivity. In R. M. Paige (Ed.), Education for the intercultural experience (pp. 21-72). Yarmouth, ME: Intercultural Press. 
Bishop, S. C. (2013). The rhetoric of study abroad: Perpetuating expectations and results through technological enframing. Journal of Studies in International Education, 17(4), 398-413.

Bourdieu, P., \& Passeron, J. C. (1977). Reproduction in education, society and culture. London, UK: Sage Publications.

Braskamp, L. A., Braskamp, D. C., \& Merrill, K. (2009, Fall). Assessing progress in global learning and development of students with education abroad experiences. Frontiers: The Interdisciplinary Journal of Study Abroad, XVIII, 101-118.

Brown, A. (2013). Waiting for superwoman: White female teachers and the construction of the neoliberal savior in a New York City public school. Journal for Critical Education Policy Studies, 11(2), 123-164.

Cameron, J. (2014). Grounding experiential learning in "thick" conceptions of global citizenship. In R. Tiessen \& R. Huish (Eds.), Globetrotting or global citizenship? Perils and potential of experiential learning (pp. 21-42). Toronto, Canada: University of Toronto Press.

Campus Compact. (2019). 2018 Global engagement survey. Retrieved from https://compact.org/2018-global-engagement-survey/

Caton, K., \& Almeida Santos, C. (2009). Images of the other: Selling study abroad in a postcolonial world. Journal of Travel Research, 48(2), 191-204.

Chang, A. (2017). "Call me a little critical if you will": Counterstories of Latinas studying abroad in Guatemala. Journal of Hispanic Higher Education, 16(1), 3-23.

Collins, L. (2019). Letting the village be the teacher: A look at community-based learning in northern Thailand. Teaching in Higher Education: Critical Perspectives, 24(5), 694-708.

Contreras, E., López-McGee, L., Wick, D., \& Willis, T. (2019). Introduction: A virtual issue on diversity and inclusion in education abroad [Special issue]. Frontiers: The Interdisciplinary Journal of Study Abroad, 1-6.

Deardorff, D. (2006). Identification and assessment of intercultural competence as a student outcome of internationalization. Journal of Studies in International Education, 10(3), 241266.

DeCuir, J. T., \& Dixson, A. D. (2004). "So when it comes out, they aren't that surprised that it is there": Using critical race theory as a tool of analysis of race and racism in education. Educational Researcher, 33(5), 26-31.

Delgado, R., \& Stefancic, J. (2017). Critical race theory: An introduction. New York, NY: NYU Press.

Denney, A. (2018, Nov 7). "IUPUI takes a different approach to racial equity through a Welcoming Campus Innovation Project." Retrieved from https://news.iu.edu/stories/2018/11/iupui/inside/07-welcoming-campus-initiative-racialequity.html

Evans, N. J., Forney, D. S., Guido, F. M., Patton, L. D., \& Renn, K. A. (2009). Student development in college: Theory, research, and practice. Hoboken, NJ: John Wiley \& Sons.

Fiedler, M. (2007). Postcolonial learning spaces for global citizenship. Critical Literacy: Theories and Practices, 1(2), 50-57.

Green, P., \& Johnson, M. (Eds.) (2014). Crossing boundaries: Tensions and transformation in international service-learning. Sterling, VA: Stylus.

Hamir, H. B., \& Gozik, N. (Eds.) (2018). Promoting inclusion in education abroad. Sterling, VA: Stylus.

Han, E., \& O’Mahoney, J. (2018, May 15). How Britain's colonial legacy still affects LGBT politics around the world. The Conversation. Retrieved from 
http://theconversation.com/how-britains-colonial-legacy-still-affects-lgbt-politics-aroundthe-world-95799

Hartman, E. (2015). Fair trade learning: A framework for ethical global partnerships. In M. A. Larsen (Ed.), International service learning: Engaging host communities (pp. 215-234). New York, NY: Routledge.

Hartman, E. (2016). Malia, the rise of the gap year, and ethical international engagement. Stanford Social Innovation Review. Retrieved from http://ssir.org/articles/entry/malia_the_rise_of_the_gap_year_and_ethical_international_eng agement

Hartman, E. (2017). Community-engaged scholarship, knowledge, and dominant discourse: A cautionary tale from the global development sector. Journal of Leadership Studies, 11(1), 17.

Hartman, E., \& Kiely, R. (2014). Pushing boundaries: Introduction to the global service-learning special section. Michigan Journal of Community Service Learning, 21(1).

Hartman, E., Kiely, R., Boettcher, C., \& Friedrichs, J. (2018). Community-based global learning. Sterling: VA: Stylus Publishing.

Hartman, E., Lough, B., Toms, C., \& Reynolds, N. (2015). The beauty of global citizenship: The problem of measurement. In B. Oomen, E. Park, M. Sklad, \& J. Friedman (Eds.), Going glocal: The theory, practice, evaluation, and experience of education for global citizenship. Amsterdam, Netherlands: Drukkerij Publishing.

Gathogo, K., \& Horton, D. (2018). The exclusionist framing of study abroad electronic advertising and its potential influence on students of color participation. Journal for the Study of Postsecondary and Tertiary Education, 3, 59-76.

Haverford College. (2017). Seeking global citizenship: Ethical photography contest. Retrieved from https://www.haverford.edu/peace-and-global-citizenship/news/seeking-globalcitizenship-ethical-photography-contest

Institute of International Education. (2018). "Profile of U.S. study abroad students, 2005/062016/17." Open Doors report on international educational exchange. Retrieved from http://www.iie.org/opendoors

la paperson. (2017). A third university is possible. Minneapolis, MN: University of Minnesota Press.

Landau, J., \& Moore, D.C. (2001) Towards reconciliation in the motherland: Race, class, nationality, gender, and the complexities of American student presence at the University of Ghana, Legon. Frontiers: The Interdisciplinary Journal of Study Abroad, 7(3), 25-59.

Larsen, M. A. (Ed.). (2015). International service learning: Engaging host communities. New York, NY: Routledge.

Lee, J., \& Green, Q. (2016). Unique opportunities: Influence of study abroad on Black students. Frontiers: The Interdisciplinary Journal of Study Abroad, XXVIII, 61-77.

Lesnick, A. (2017). Thinking together: Between risk, restriction and learning in a U.S.-Ghana collaborative. Collaborations: A Journal of Community-Based Research and Practice, 1(1).

Lesnick, A., \& Bahn, H. (2018). Help [not] wanted: Neo-liberal discourses of leadership against community knowledge and control in comparative context. Power and Education, 11.

Lopez-McGee, L., Comp, D., \& Contreras, E. (2018). Underrepresentation in education abroad: A review of contemporary research and future opportunities. In H. Barclay Hamir \& $\mathrm{N}$. Gozik (Eds.), Promoting inclusion in education abroad: A handbook of research and practice. Sterling, Virginia: Stylus. 
McTighe Musil, C. (2009). Educating students for personal and social responsibility: The civic learning spiral. In B. Jacoby et al. (Eds.), Civic engagement in higher education (pp. 49-65). San Francisco, CA: Jossey-Bass.

Milem, J. F., Chang, M. J., \& Antonio, A. L. (2005). Making diversity work on campus: A research-based perspective. Association of American Colleges and Universities.

Mogford, E., \& Lyons, C. J. (2019). The impacts of international service learning on a host community in Kenya: Host student perspectives related to global citizenship and relative deprivation. Frontiers: The Interdisciplinary Journal of Study Abroad, XXXI(2), 86-104.

Morais, D. B., \& Ogden, A. C. (2011). Initial development and validation of the global citizenship scale. Journal of Studies in International Education, 15(5), 445-466.

Onyenekwu, I., Angeli, J. M., Pinto, R., \& Douglas, T. (2017). (Mis)representation among U.S. study abroad programs traveling to the African continent: A critical content analysis of a Teach Abroad program. Frontiers: The Interdisciplinary Journal of Study Abroad, XXIX(1), 68-84.

Padgett, T. (2006, Apr 12). The most homophobic place on earth? Time Magazine. Retrieved from http://content.time.com/time/world/article/0,8599,1182991,00.html

Padrón, M. (2018). Good intent and grave missteps: How I went from Latinx in the US to white in Nicaragua, and the lessons in between. Campus Compact. Retrieved from https://compact.org/good-intent-grave-missteps-went-latinx-united-states-white-nicaragualessons-part-1-2/

Parker, K., Menasce Horowitz, J., Brown, A., Fry, R., Cohn, D., \& Igielnik, R. (2018). What unites and divides urban, suburban, and rural communities. Pew Research Center. Retrieved from https://www.pewsocialtrends.org/2018/05/22/demographic-and-economic-trends-inurban-suburban-and-rural-communities/

Porfilio, B., \& Hickman, H. (Eds.). (2011). Critical service-learning as revolutionary pedagogy: A project of student agency in action. Charlotte, NC: Information Age Publishing.

Prins, E., \& Webster, N. (2010). Student identities and the tourist gaze in international servicelearning: A university project in Belize. Journal of Higher Education Outreach and Engagement, 14(1), 6-32.

Reynolds, N. (2014). What counts as outcomes? Community perspectives of an engineering partnership. Michigan Journal of Community Service Learning, 20(1), 79-90.

Reynolds, N., \& Ermilio, J. (2015). Saying it doesn't make it so: Do we listen and act when the host community tells us what they want? In M. Larsen (Ed.), International service learning: Engaging host communities. New York, NY: Routledge.

Russel y Rodríguez, M. (2007). Messy spaces: Chicana testimonio and the undisciplining of ethnography. Chicana/Latina Studies, 7(1), 86-121.

Salisbury, M. H., Paulsen, M., \& Pascarella, E. T. (2011). Why do all the study abroad students look alike? Applying an integrated student choice model to explore differences in the factors that influence white and minority students' intent to study abroad. Research in Higher Education, 52(2), 123-150.

Santiago-Ortiz, A. (2019). From critical to decolonizing service-learning: Limits and possibilities of social justice-based approaches to community service-learning. Michigan Journal of Community Service-Learning, 25(1), 43-54.

Schram, S. (2012). Phronetic social science: An idea whose time has come. In B. Flyvbjerg, T. Landman, \& S. Schram (Eds.), Real social science: Applied phronesis (pp. 15-26). Cambridge, UK: Cambridge University Press. 
Sweeney, K. (2013). Inclusive excellence and underrepresentation of students of color in study abroad. Frontiers: The Interdisciplinary Journal of Study Abroad, 23, 1-21.

Tervalon, M., \& Murray-García, J. (1998). Cultural humility versus cultural competence: A critical distinction in defining physician training outcomes in multicultural education. Journal of Health Care for the Poor and Underserved, 9(2), 117-125.

Tharps, L. (2014, Nov 18). The case for Black with a capital B. The New York Times. Retrieved from https://www.nytimes.com/2014/11/19/opinion/the-case-for-black-with-a-capital-b.html

Tuck, E. (2009). Suspending damage: A letter to communities. Harvard Educational Review, 79(3), 409-427.

Twombly, S. (1995). Piropos and friendships: Gender and culture clash in study abroad. Frontiers: The Interdisciplinary Journal of Study Abroad, I(Fall), 1-27.

United States Census Bureau. (2019). Quick facts: United States. Retrieved from https://www.census.gov/quickfacts/fact/table/US/RHI825218\#RHI825218

Vande Berg, M., Paige, R. M., \& Hemming Lou, K. (2012). Student learning abroad: What our students are learning, what they're not, and what we can do about it. Sterling, VA: Stylus.

Wick, D., Willis, T. Y., Rivera, J., Lueker, E., \& Hernandez, M. (2019). Assets-based learning abroad: First-generation Latinx college students leveraging and increasing community cultural wealth in Costa Rica. Frontiers: The Interdisciplinary Journal of Study Abroad, XXXI(2), 63-85.

Yosso, T. J. (2005). Whose culture has capital? A critical race theory discussion of community cultural wealth. Race Ethnicity and Education, 8(1), 69-91.

Zemach-Bersin, T. (2007). Global citizenship \& study abroad: It's all about U.S. Critical Literacy: Theories and Practices, 1(2), 16-28.

Zemach-Bersin, T. (2008). American students abroad can't be global citizens. The Chronicle of Higher Education, 54(26), A34. 